\section{Auricular Inflammation}

SIR,-I had opportunity to notice during ten years of service in China four cases of a peculiar otochondritis in the cartilage of the external ear, with the signs of acute inflammation, redness, swelling, and localized pain. In such a case the auricula is tender and sometimes shows an oedematous swelling, which subsides on pressure, causing considerable pain. This otochondritis disappears after a few weeks, leaving the auricula enlarged and the cartilage thickened. After some time-weeks or months - the next attack would set in with a very similar course, possibly a bit of fever, and clear up again. After years, as I have seen in one case- a middle-aged woman of Chinese racethe auricula becomes hard as a board, inflexible, and stands at a right angle to the sagittal plane of the body. The skin is dark brown, hyperpigmented, and the patient complained of being unable to lie on the diseased side.

I could not find any cause for this disease. One patient had a positive Kahn test, and antisyphilitic treatment had no influence on the course of the disease. I tried local application of tincture of iodine, cold and hot fomentations, and sulphonamides by mouth, all sine effectu. Could somebody enlighten me on this subject or relate similar experiences, especially in tropical countries? - I am, etc.,

London, W.1.

\section{W. WINTERSTEIN.}

\section{Treatment of Varicose Veins}

SIR,-The article on the treatment of varicose veins by Prof. A. M. Boyd and Mr. D. J. Robertson (Sept. 20, p. 452) contains points of much practical interest, some of which call for further discussion. The 12 cases of deep thrombosis seen in a space of five months must surprise most of your readers. Many years ago I had one such case in a man of 70 to whom I had given some injections of, I think, quinine below the knee. The following week he reported with his whole saphena vein thrombosed to the groin. He did not turn up again for a few months and then said that in the meantime he had had pneumonia, but my inquiry to his doctor as to whether he thought the "pneumonia" was an embolic condition or whether it was a primary condition which might have caused the deep thrombosis failed to elicit a reply. I have never seen deep thrombosis following groin ligation plus injection. I wish the authors had said more about the technique used in the 12 cases and the amount and nature of solution employed.

The authors repeat the usual statement that it is important to ligate the saphena tributaries in the groin to prevent recurrence and show a photograph to illustrate a recurrence where this has not been done. As it is virtually impossible to get a clear view of the sapheno-femoral junction without dividing these tributaries it is safe to assume in such cases of recurrence that effective ligation has not been done, but the point is academic. The writers refer to temporary oedema of the ankle and lower part of the leg which may follow injections alone. I have had this annoying complication from time to time, but, owing to its transient nature, have wondered whether it might be caused by unduly prolonged reflex spasm spreading to some of the sub-fascial veins. I do not dispute their explanation, however, that it may be due, in part at least, to some degree of thrombosis in the deeper veins.

The authors do not refer to sclerosing agents, but the choice of these is of some importance. Thirteen years ago I started experimenting with carbolic-glycerin mixtures of various strengths, and for the last eight years have used a solution of $2 \%$ liquid phenol in $30 \%$ glycerin measured by volume. This solution is an adequate sclerosing agent, seldom causes undue reactions, is relatively harmless to the subcutaneous tissues, possibly due to the hygroscopic qualities of the glycerin leading to its dilution with tissue fluids, and is cheap and antiseptic, and can be stored in bulk. Haemoglobinuria has not been reported from its use, though it occurred at times with higher strengths. $15 \mathrm{ml}$. is the standard amount given at any one sitting, though 20 or $25 \mathrm{ml}$. has frequently been injected in divided doses. The only disadvantage to report is that vertigo sometimes occurs after injecting $5 \mathrm{ml}$. at one point, but this passes off in a minute or so, and further injections do not cause a return of the giddiness. A modification of this solution has been reported on by Dodd in this Journal (March 15, p. 366).

Another point in treatment I may be allowed to mention here is that the saphena vein may be thrombosed by mechanical damage to the intima. For this purpose a "scraper" is used. This instrument consists of a metal tube $(25 \mathrm{in} .(63 \mathrm{~cm}$.) is a convenient length) with a screw joint in the middle for ease of portability; and at the end is fixed a metal cylinder with a rounded end and roughened surface, which is passed down the saphena trunk after its division in the groin. The instrument will not pass a marked tortuosity in the vein, but obstructing valve cusps can be broken down safely with a few judicious jabs, and in most cases the roughened cylinder will reach at least as far as the knee, and in large veins can often be pushed its full length to the middie third of the leg. During this proceeding escape of blood is prevented from the upper end of the vein by a piece of catgut passed twice round the vein, the ends being held by an assistant. In the case of the left leg, when the scraper has been passed to its limit with the right hand, the fingers of the left hand are pressed against the vein, with the little finger opposite its lower end, and the scraper is moved up and down a few times and rotated if desired. This procedure is repeated a hand's breadth at a time in an upward direction till the whole length of vein is dealt with. If it is desired to inject the vein at operation, the tube of the instrument is filled with solution to displace air before it is passed, and when it has been pushed down to its limit $10 \mathrm{ml}$. of the solution mentioned above is injected and the "scraping" then proceeded with.

Boyd and Robertson give evidence to suggest that injection below the knee is unlikely to be harmful, and, as mechanical thrombosis of the trunk above the knee cannot affect the intima of the deeper veins, the technique described appears to meet their criteria of safety in treatment. This may account for the lack of anxiety I have had with the method during the past four to five years.

The instrument is made by Messrs. Phillip Harris and Co., 44, Edmund Street, Birmingham, 3.-I am, etc.,

Birmingham.

J. W. RIDDOCH.

\section{Homosexuals in Prison}

SIR,-All workers in this field welcome Dr. F. H. Taylor's article (Oct. 4, p. 525), which puts forward the evidence of facts to take the place of speculation and theory. As he rightly says, it is the true invert whose case is of most interest, and several matters arise from his report of the 13 prisoners of this type who came under his care.

First, the facts refute a popular misconception that the natural homosexual is attracted to small boys, as among 13 true inverts only one was interested in boys. An invert turns towards adults of his own sex as naturally as a normal man is sexually attracted by a woman as a potential mate rather than by a child. ${ }^{1}$ Homosexual offences against children are almost exclusively the prerogative of the pseudo-homosexual group, wherein over $50 \%$ exhibit mental subnormality, many of them being of the same mental age as the children they seek to seduce.

Secondly, the evidence from the series of true inverts might be used to give support to the theory that seduction in early youth or childhood is a dominant factor in the production of homosexuality, which is the view taken by Sir Norwood East and W. H. Hubert ${ }^{2}$ and opposed by E. A. Bennet and others. ${ }^{3}$ This point of course is supremely important in connexion with the social as well as the clinical aspects of homosexuality. But the support given by this investigation is considerably weakened by a closer examination of the evidence which Dr. Taylor quite impartially puts forward. Among these 13 men androgynous physique was present in six cases: obviously the physique could not have been caused by the seduction, though the reverse might well have been true. The fallacy of post hoc ergo propter hoc can be excluded only by comparable statistics from a control series of non-homosexual prisoners. Some form of homosexual activity which can only be described as seduction is the experience of large numbers of public-school boys during their early 'teens, the incidence varying widely from school to school, but in some places it is certainly of the order of $50 \%$; a similar figure is probable in other social strata, and it may well be even higher among the sub-intellectual group that contributes so largely to the prison population. The postulated connexion between seduction and later homosexuality can therefore be established only if a similar investigation among a control series of prisoners reveals a difference that is statistically significant. It is to be hoped that this evidence will be forthcoming, for without a knowledge of the facts further discussion is useless. 
Thirdly, the evidence from Brixton prison appears to support the alleged connexion between natural homosexuality and sexual perversion, which is the view put forward by Sir Norwood East and W. H. Hubert ${ }^{2}$ and Clifford Allen, ${ }^{4}$ and opposed by Havelock Ellis and others. J. A. Symonds (in an unpublished essay) admits that, although " a far larger proportion of mental disturbance and nervous hypersensitivity can he proved in Urnings than in normal men, in a vast majority of cases the Urning owing to present laws and social prejudices cannot, like other men, obtain a simple and easy satisfaction of his inborn sexual desires, which for him are as natural as swimming to a fish. It is this forcible suppression of an instinct so deeply rooted in his nature which originates the morbid symptoms that may often be observed in the Urning." The same author attributes to homosexual fears and guilt "at least half of the suicides of young men." Bernard Shaw has stated categorically that " homosexuality implies no general depravity whatever." The validity of evidence to the contrary which might be drawn from the present series of cases is dependent entirely upon the support of a series of controls. An examination of the 198 prisoners (presumably males) charged with heterosexual offences during the same period would probably yield a percentage of degeneracy comparable with that found in the homosexual group, and this again is valuable evidence that should be available before discussion can proceed with profit. But in any case it would be as unreasonable to draw conclusions about clinical and social (as distinct from antisocial) homosexuality from a series of homosexual prisoners as to base arguments concerning normal heterosexuality on the findings in a similar group of heterosexual offenders.

General deductions as to treatment would be open to the same error. It would be as unlikely that patients from this series of cases could respond to psychotherapy by making a good social adaptation (even if their homosexuality were left untouched) as that their heterosexual fellow prisoners could be educated to become happy fathers and husbands. Only the dregs of both classes find their way into the prisons, and unfortunately it is only from this group that statistical evidence about homosexuality can be collected. This evidence is not applicable to the socially adapted natural invert.

Lastly, may the opportunity be taken to correct an error that appeared in the B.M.J. last year, and which still stands ufichallenged, namely - that "buggery" is a scriptural term? The appellation of bougre (Fr: Bulgarian) was given to the ultrapuritanical sect of the Albigenses in the South of France during the eleventh century A.D. on account of their association with the Bogomils, or Bulgarian heretics-heretics only by reason of their steadfast and unyielding opposition to Catholic orthodoxy, for which the sect was exterminated in the Albigensian "Crusade" of 1209.6 The imputation of unnatural vice (which has been entirely discredited) was the invention of the fertile mind of Pope Innocent III, who was himself a repressed homosexual and a fanatical persecutor of all forms of sexual heterodoxy real or imagined.

Cornwall.

D. Stanley-Jones.

REFERENCES

1 Anomaly, The Invert, 1929, London; Stanley-Jones, D., Proc. roy. Soc. Med., 1947, 40, 590.

2 Report on the Psychological Treatment of Crime, 1939, H.M.S.O., London.

3 Bennet, E. A., British Medical Journal, 1946, 1, 289, 450; Rosanoff, A. J., Manual of Psychiatry, 7th ed., 1938 , p. 556 , New York; Quoted by Dillon, F., British Medical Journal, 1946, 1, 450 ; ' Stanley-Jones, D., Lancet, 1947, 1, 366.

4 The Sexual Perversions and Abnormalities, 1940, London.

5 Personal communication, 1947.

6 Stanley-Jones, D., Med. Pr., 1946, 215, 391.

\section{Another Foetus Crics}

SIR,- Interest and speculation have been aroused by reading Dr. E. Curphey's letter (Sept. 27, p. 508). During induction of labour on Oct. 8 in a para-2 woman at the 39th week of pregnancy by means of a Drew-Smythe catheter I was astonished to observe the same phenomenon. The head was in the brim of the pelvis. While manipulating the catheter I followed my usual custom of engaging the patient in conversation. On this occasion I was asking her whether she had read in the papers of the baby who cried before being born.

After withdrawing $24 \mathrm{oz}$. $(680 \mathrm{ml}$.) of liquor I left the catheter in situ for another minute in order to remove any further liquor that could be expressed from the uterus. The baby was particularly active and moved the catheter several times. Immediately after withdrawing the catheter the mother said to me, "My baby is crying too." Needless to say I did not believe her and suggested that $I$ had put the idea into her head. Half a minute later I asked the midwife in attendance to listen to the foetal heart. On placing the foetal stethoscope rather nearer the foetal head than usual, she replied excitedly, "The baby is crying." 'At this stage, from my position at the foot of the patient, who was still in the lithotomy position, I heard a sound resembling a smothered gurgle. I then used the foetal stethoscope and without a doubt heard the baby cry.

The baby was subsequently extracted with forceps, alive and well, 15 hours later. I too was unfortunate in not getting further medical confirmation in order to convince my sceptical colleagues, and the baby could not be induced to repeat the performance.

George H. Ryder, however, has reviewed ${ }^{1}$ some of the 123 authentic cases of vagitus uterinus reported in the literature between the years 1800 and 1941 . He found that there was a foetal mortality of nearly 1 in 5 , and in $85 \%$ of cases operative interference was required. One cannot, of course, infer that the mortality or the interference was directly related to impending asphyxia of the foetus. Munro Kerr in his textbook ${ }^{2}$ has reported that on two occasions he heard the foetus cry in utero while an internal version was being performed. It is obvious that the introduction of air into the uterus is necessary before the foetus can cry, and possibly somatic stimulation from the introduced instrument or hand also helps to overcome the inhibition of respiratory movement which Barcroft has found ${ }^{3}$ to exist during the latter period of foetal life. In this particular case both conditions seem to have been present.-I am, etc., Oxford. JeAn Burton-Brown.

\section{REFERENCES}

1 Amer. J. Obstet. Gynec., 1943, 46, 867.

2 Operative Obstetrics, 4th ed., 1937, London.

8 Researches on Pre-Natal Life, 1946, Oxford.

\section{Vaginal Temperature}

SIR,-The case reported by Dr. John Hankinson (Oct. 11, p. 574) of a woman having passed a clinical thermometer into the bladder while endeavouring to take her vaginal temperature should serve to emphasize the undesirability of this extraordinary procedure. That the recording of basal temperatures is of great value in the study of cases of infertility will be acknowledged by most of those who have had experience of them and have taken pains to see that their patients record them properly ; that the determination of the "safe period" by means of basal temperatures can be a satisfactory contraceptive technique might also be allowed, though doubts might validly be expressed concerning this; but that patients should be subjected to the inconvenience and, to judge from Dr. Hankinson's report, the potential dangers of inserting clinical thermometers into their vaginae in order to estimate their basal temperatures seems utterly ludicrous.

Is the temperature of the vaginal cavity supposed to carry some especially recondite significance from the standpoint of conception, its failure, or its prevention? Or is the placing of a clinical thermometer beneath the tongue, followed by closure of the lips, too simple a procedure sufficiently to impress the patient that the temperature record so obtained is of value? If anyone who has been advising his patients to take their vaginal temperatures does not realize that oral temperatures taken in the same way will yield just as much information, then the best advice that can be given is that he should try the latter technique and see for himself. And the same can be said for rectal temperatures, the taking of which is scarcely less inconvenient or distasteful to the patient than is that of vaginal temperatures.

That the situation as it appears to exist is almost comic can be judged from the suggestion of Dr. Hankinson that a specially designed thermometer should be employed for taking vaginal temperatures, which calls to mind the true instance of a woman, instructed to take her vaginal temperatures, apalogizing for not having done so because none of the chemists' shops she had tried had stocked a vaginal thermometer.-I am, etc.,

London, N.W.6.

G. I. M. SWYER. 